\title{
Editorial: Adapting to survive
}

Adapting to change has always been one of the basic requirements of life. In the long run, the price of not adapting is failure to survive. Change has, of course, been getting faster in every way since the industrial revolution began. But it now presents a psychological threat to almost everyone. This threat comes from the clash between the increasing need to adapt and those strong forces, both within people and within societies, which seek to keep things as they are.

From the mental health point of view, we know that stability is important. A healthy personality is most likely to develop in a home where the child can rely on things and people around him not changing from day to day. The sense of personal identity is difficult to establish when there are no constant landmarks, and the most important of these are the parents themselves. But outside the immediate home, there needs to be a neighbourhood which can be seen and understood as one particular place-not just an unidentifiable bit of urban sprawl.

In 'The Territorial Imperative', Robert Ardrey showed that there are strong bonds between all living creatures and the areas they inhabit. If places are meant for people, and not vice versa, these feelings should be an important influence in urban redevelopment and in the creation of new living areas. Plausible arguments are advanced for 'linear growth' and other kinds of development which would turn most of this country into a low-density Los Angeles. This is not adapting to change, but throwing away the whole valuable system of psychological bonds between people and their environment.

In the same way, rebuilding need not be a wholesale clearance, followed by the creation of something completely strange. Landmarks and areas of old building can be left to provide continuity and preserve the spirit of a neighbourhood. As often as not, this will make economic good sense, as well as being a means of psychological support to the population.

This kind of stability is the background on which people can then adapt themselves to the inevitable changes imposed by modern technology. The rate of change is now faster than at any previous time in history. This means that people's working skills are very likely to become obsolete and enormous numbers will need to change their kind of work. Our old basic industries, such as coal, textiles and railways have already given up a large proportion of their working force and are likely to become even smaller before long. Because these industries have been mainly concentrated in the older industrial areas, a change of job is very likely to mean also a change of home. It may also mean separation from a closely knit community, with which the worker was strongly identified. This separation will cause stress.

The economic problems of labour mobility and redeployment have not lacked discussion. But the psychological problems are no less important and can have a big effect on industrial performance. Men who have given the greater part of their working lives to a particular industry may suffer very seriously in morale when they find they are no longer needed by it. Consultation and psychological preparation can overcome this to a large extent, and so can good facilities for re-training. Where there has to be a change of home, the whole family is involved and the National Coal Board, for instance, has developed good arrangements for helping miners' families with the difficulties of moving - both practical and psycho logical.

But problems of mobility are not only in obsolescent industries. Technological change, fiercer competition and better education means that people in general change their jobs more often. With younger families, the burden will be likely to fall most heavily on the wife - away from her own family, amongst stranget ts $^{5}$ and probably tied to the house by small children. $A^{5}$ a society, we have not yet found ways of helping people like this to adjust to change and to lead a better life. They may come to professional mental health services in a variety of ways, and more nursery classe $e^{5}$ would probably be the biggest single source of help. But in the long run, it is the community's own con cern that is most needed for people adversely affected by change. 